\title{
Sequential measurement of aminotransferase activities by amperometric biosensors
}

\author{
Ku-Shang Chang a,b,*, Chen-Kai Chang ${ }^{\mathrm{a}, \mathrm{c}}$, Su-Fen Chou ${ }^{\mathrm{a}, \mathrm{d}}$, Chien-Yuan Chen ${ }^{\mathrm{a}, * *}$ \\ a Department of Biochemical Science and Technology, Graduate Institute of Microbiology and Biochemistry, \\ National Taiwan University, Taipei, Taiwan \\ ${ }^{\mathrm{b}}$ Department of Food Science, Yuanpei University, Hsinchu, Taiwan \\ ${ }^{c}$ Department of Food Science and Technology, Chia Nan University of Pharmacy and Science, Tainan, Taiwan \\ ${ }^{\mathrm{d}}$ Department of Biotechnology, Chia Nan University of Pharmacy and Science, Tainan, Taiwan \\ Received 30 July 2006; received in revised form 29 November 2006; accepted 1 December 2006 \\ Available online 31 January 2007
}

\begin{abstract}
An L-glutamate biosensor modified by cation exchanger membrane on a palladium (Pd) electrode was designed for the purpose of preventing interferences and electrode fouling during the measurement of serum AST and ALT activities. The rate of signal increase obtained by our sensor for the determination of AST and ALT activity was 0.259 and $0.596 \mathrm{nA} / \mathrm{min} \mathrm{U}^{-1} 1$ and the response of the sensor to AST and ALT activity were linear over the range of 8-200 and 8-250 $\mathrm{U}^{-1}$, respectively. Both AST and ALT activities could be measured sequentially by injecting the serum into a solution containing L-aspartate and $\alpha$-ketoglutarate. The rate of current increase was relative to AST activity. The activity of ALT was sequentially determined after addition of L-alanine into the solution. The change in the current increase rate after the addition of L-alanine was proportional to the ALT activity. By using the proposed biosensor, the interference of $1 \mathrm{mM}$ ascorbic acid was negligible on a dynamical aminotransferase determination when the dynamic data are taken after the steady state of an elevated baseline has been reached. The proposed L-glutamate biosensor provides adequate sensitivity for the measurement of AST and ALT and is expectable to be applied for rapid blood screening of AST and ALT activity in clinical sample.
\end{abstract}

(C) 2007 Elsevier B.V. All rights reserved.

Keywords: AST; ALT; L-Glutamate biosensor; Amperometric biosensor; Nafion; Pd

\section{Introduction}

The activities of AST and ALT in serum are important indicators of liver function and several other symptoms (Rietz and Guilbault, 1975; Karmen, 1955; Reitman and Frankel, 1957; Clark, 1987). Voluntary blood donation has been implemented successfully in Taiwan. However, a total of 211 (3.3\%) in 6484 blood donors detected to be elevated in ALT levels

\footnotetext{
* Corresponding author at: Department of Food Science, Graduate Institute of Biotechnology, Yuanpei University of Science and Technology, Hsinchu, Taiwan. Tel.: +886 3 5381183x8483; fax: +886 35385353 .

** Corresponding author at: Department of Biochemical Science and Technology, Institute of Microbiology and Biochemistry, National Taiwan University, No. 1, Sec. 4, Roosevelt Road, Taipei 106, Taiwan. Tel.: +8862 23630231 x3256; fax: +886223661696

E-mail addresses: tommy.first@msa.hinet.net (K.-S. Chang), chenyuan@ntu.edu.tw (C.-Y. Chen).
}

by serological tests (Shi, 1997). Since the blood with high ALT levels have to be discarded, as they are unsuitable to be used for blood transfusion. Thus, a rapid and low cost devices for rapid blood screening of ALT activity in routine blood donation is needed. This will reduce the expenses for the blood donation. Although portable amperometric biosensor that uses glucose oxidase has been commercialized for monitoring diabetes (Magner, 1998), amperometric biosensors for the measurement of aminotransferase activity are still poorly developed.

The enzymatic reactions of AST and ALT may be summarized as follows (Rietz and Guilbault, 1975).

$l$-aspartate $+\alpha$-ketoglutarate $\stackrel{\text { AST }}{\longrightarrow}$ oxaloacetate $+l$-glutamate

$l$-alanine $+\alpha$-ketoglutarate $\stackrel{\mathrm{ALT}}{\longrightarrow}$ pyruvate $+l$-glutamate 
When using an amperometric sensor to measure enzymatic activity, follow-up reactions, where hydrogen peroxide is a final product is required (Nagy et al., 1998). We can achieve this by further oxidation of L-glutamate or pyruvate after the ALT and/or AST catalytic reaction (Issberner et al., 2002; Chang et al., 2003). GLOx-based electrodes have the following advantages over pyruvate-sensing electrodes (Nagy et al., 1998; Kihara et al., 1984a,b; He and Chen, 1997) for the measurment of aminotransferase: (1) GLOx is far more stable than pyruvate oxidase upon storage (Mizutani et al., 1998), (2) no reagents other than an oxygen-containing buffer solution are required for operating GLOx-based electrodes, whereas the addition of cofactors (i.e. thiamine pyrophosphate and $\mathrm{Mg}^{2+}$ ) is required for the use of pyruvate oxidase-based electrodes (Mizutani et al., 1998; Uollenberger et al., 1989; Compagnone et al., 1992; Cooper et al., 1991; Kusakabe et al., 1983) and (3) the electrode uses only one enzyme, the manufacture of which is simpler than electrodes using oxalacetate decarboxylase and pyruvate oxidase on the same electrode. Therefore, L-glutamate sensor was use for the measurement of aminotransferase.

As described above, amperometric biosensors for the measurement of aminotransferase activity are still poorly developed. Among the limited number of reports, Cooper et al. (1991) developed an L-glutamate biosensor by passive adsorption of the enzyme onto the electrode surface. Compagnone et al. (1992) and Mizutani et al. (1998) reported permselective membrane based on the solute size with cutoff of 100-Da to protect the electrode from the interference of ascorbic acid for the measurement of aminotransferase activity. However, the calibration curve must be adjusted after every five analyses because response decreases continuously (Compagnone et al., 1992). The electrochemical oxidation of ascorbic acid generates the dehydroascorbic acid which can be adsorbed over the electrode (Matos et al., 2000; Arya et al., 2000; Pournaghi-Azar and Ojani, 1997; Moussyd et al., 1993; Geise et al., 1991), which may account for the decreasing in response. Palladium electrode, opposite to the most common electrodes, was also reported able to prevent the fouling of the electrode in solutions containing uric acid, ascorbic acid and urine samples (Matos et al., 2000; Johnston et al., 1995; Lim et al., 2005).

In this study, a biosensor composed of immobilized Lglutamate oxidase in a photo-crosslinkable polymer membrane on a Nafion coated palladium electrode was fabricated to prevent interferences and electrode fouling for the kinetic-based measurement of serum AST and ALT activities. The sensitivity of proposed biosensor for the measurement of AST and ALT activity was also evaluated and compared with other biosensor described in literature.

\section{Materials and methods}

\subsection{Reagents and materials}

Bovine serum albumin (BSA), monosodium glutamate (MSG), L-alanine, L-aspartate, glutaraldehyde, $\alpha$-ketoglutarate $(\alpha-K G)$, human sera, ALT (EC 2.6.1.2, from porcine heart) and AST (EC 2.6.1.1, from porcine heart) were purchased from
Sigma Chemical Co. (St. Louis, USA), and PVA-SbQ (degree of polymerization 1700 , degree of saponification $87 \%$ ) was purchased from Toyo Gosei Kogyo Chemical (Tokyo, Japan). Nafion (perfluorinated ion-exchange resin, $5 \%(\mathrm{w} / \mathrm{v})$ solution in lower alcohol/water) was purchased from Aldrich (Steinheim, Germany) and used as supplied. The enzyme L-GLOx (EC 1.4.3.11) was produced from Streptomyces sp. NTU 3304 in our laboratory. The palladium strip electrode was obtained from Boehringer-Mannheim. All other reagents were of analytical grade.

\subsection{Electrode modification}

A commercial glucose test strip (Boehringer-Mannheim) consisting of two palladium strip electrodes was used. The electrodes of the test strip are insulated with PVC except for the enzyme-loaded pad and connecting area. The enzyme-loaded pad is covered with dried enzyme and a number of additives to act as the reaction area. The connecting area is used to connect these electrodes to the glucose meter.

In this study, the palladium connecting strip of the commercial electrode were used as electrode by cutting off the enzyme loaded pad. The prepared palladium strips were then modified and connected to a laboratory-built potentiostat as the work and counter electrodes. The L-GLOx was then immobilized onto the connecting area of the commercial electrode.

\subsection{Enzyme immobilization}

Prior to enzyme immobilization, the Nafion membrane was placed on the electrode by covering the working area with $0.5 \mu \mathrm{l}$ of ethanolic solution containing $5 \mathrm{wt} . \%$ of Nafion and dried for $8 \mathrm{~h}$ at room temperature. The enzymes were immobilized by a combination of PVA-SbQ photocross-linking and glutaraldehyde exposure. The enzyme solution with activity of $70 \mathrm{U} \mathrm{ml}^{-1}$ was prepared by mixing $50 \mathrm{mg}$ PVA-SbQ, $10 \mathrm{mg} \mathrm{BSA}$ and $140 \mathrm{mg}$ of L-GLOx with activity of $100 \mathrm{U} \mathrm{ml}^{-1}$ and $1 \mu \mathrm{l}$ of this mixture was deposited onto the active area of the electrode, the sensor was then placed in a dark sealed box containing glutaraldehyde vapour. The box was kept at $4{ }^{\circ} \mathrm{C}$ for $12 \mathrm{~h}$ to complete crosslinking, then the sensor was exposed to UV light for $25 \mathrm{~min}$.

\subsection{Apparatus and procedure}

Amperometric measurements were performed using a laboratory-built potentiostat. Input and output signals from the potentiostat were coupled to a PC (Pentium $166 \mathrm{MHz}$ ) using a peripheral interface card (AT-MIO-16E, National Instruments, Austin, Texas, USA). The interface card consisted of a 16-channel analog-to-digital (A/D) converter (12 bit) and a 2-channel digital-to-analog (D/A) converter (12 bit). Voltage output, data display and recording were programmed using the LabVIEW 5.1 software package (National Instruments, Austin, Texas, USA). All measurements were taken with a threeelectrode system using an $\mathrm{Ag} / \mathrm{AgCl}$ electrode as a reference and a modified commercially palladium strip $\left(4.8 \mathrm{~mm}^{2}\right)$ as the 
working and counter electrodes. The sensor exhibited an anodic response to hydrogen peroxide starting at $+0.2 \mathrm{~V}$, reaching its diffusion current limit at about $+0.4 \mathrm{~V}$. In order to minimize the interference from electro-active species (e.g. ascorbic acid and uric acid), an operation potential of $+0.4 \mathrm{~V}$ versus $\mathrm{Ag} / \mathrm{AgCl}$ was selected for the following tests. The working solution was $9.9 \mathrm{ml}$ PBS buffer ( $\mathrm{pH}$ 7.0) in a cylindrical cell, with temperature controlled using a thermostat. All experiments were carried out at $35^{\circ} \mathrm{C}$ after consideration of normal body temperature and the stability of the electrode at this temperature. For the amperometric measurement of MSG, $0.1 \mathrm{ml}$ of MSG solution was injected into the test solution using a microsyringe when a steady state of the testing-system had been obtained. The baseline current was measured, and then, following the injection of MSG, the response current was displayed and simultaneously logged by the computer until a steady state was achieved. Magnetic stirring during the operation was used to ensure the homogeneity of the solution. The difference between the baseline and the steady-state current was used to calculate the concentration of MSG.

For the determination of AST and ALT activities in serum, unless otherwise stated, all the solutions used in ALT determinations were prepared with $100 \mathrm{mM}$ PBS buffer ( $\mathrm{pH}$ 7.0) containing $1 \mathrm{mM} \alpha$-ketoglutarate and $100 \mathrm{mM}$-alanine as substrates. The measurements with AST were made in $100 \mathrm{mM} \mathrm{pH}$ 7.0 PBS buffer containing $1 \mathrm{mM} \alpha$-ketoglutarate and $25 \mathrm{mM} \mathrm{L-}$ aspartate. Commercial preparations of porcine heart ALT and AST dialysed against the appropriate buffer to remove ammonium sulfate prior to spiking into the serum samples. A given volume $(4 \mathrm{ml})$ of buffered substrate-containing reagent solution was added into the reaction cell and in contact with the electrodes. The cell was closed and connected to the measuring apparatus. The amperometric current was recorded continuously at $0.4 \mathrm{~V}$ working electrode potential. After the current decreased to its low initial or background level, solution doses of known AST and/or ALT activity, typically in $1 \mathrm{ml}$ aliquot, was added and evenly distributed by the magnetic stirrer in the reaction cell. The current-time curve was recorded. The initial rate of current increase, which was recorded two minutes after the serum sample was added, was compared with the responses obtained for standard solutions determined by the Sigma AST or ALT assay kit, to determine a calibration graph. For sequential determination of AST and ALT, L-alanine was added into the reaction cell after the measurement of AST activity as described above. The current-time curve was recorded. The different in slope between before and after adding L-alanine was relative to the ALT activity.

\section{Results and discussion}

\subsection{The measurement of ALT and AST activities}

As shown in Fig. 1, the sensitivity of our L-glutamate sensor was inhibited by $\alpha$-ketoglutarate and L-aspartate, and also inhibited by a high concentration of L-alanine. An optimum concentration of substrate was required to achieve a maximum AST and/or ALT sensitivity. When adding ALT standard solu-

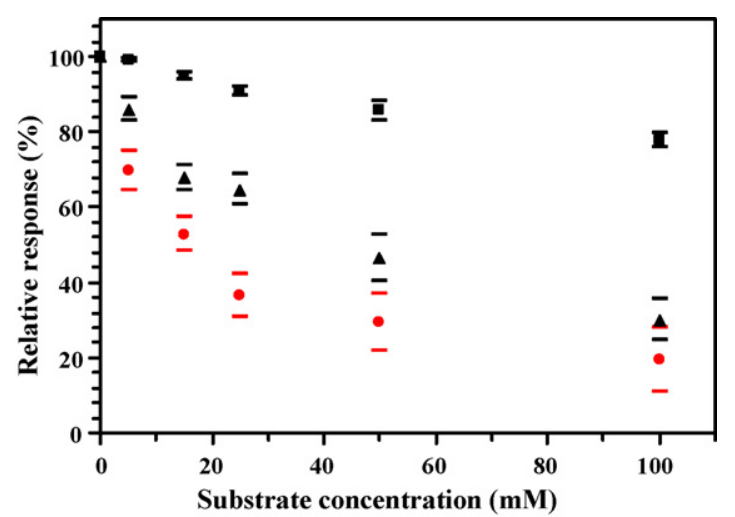

Fig. 1. Effect of substrate concentration on the response of the L-glutamate

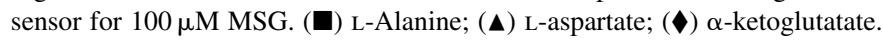
The experiments were operated in $0.1 \mathrm{M}$ PBS, buffer $(\mathrm{pH} 7.0)$ at $35^{\circ} \mathrm{C}$. The polarizing potential applied to the sensor was $0.4 \mathrm{~V}$ vs. $\mathrm{Ag} / \mathrm{AgCl}$. Each data is the mean value of three measurements.

tions into the working solution in the reaction cell, the current increased with extension of reaction time. The optimal ration of $\mathrm{L}$-alanine and $\alpha-\mathrm{KG}$ regarding sensor sensitivity was made at a concentration of $30 \mathrm{U} \mathrm{l}^{-1}$ GPT by adding $2 \mathrm{ml}$ of GPT standard solution into $4 \mathrm{ml}$ of the working solution in the reaction cell. The final concentration of $\alpha-\mathrm{KG}$ in the working solution was varied in the range from 0 to $15 \mathrm{mM}$ while the $\mathrm{L}$-alanine concentration was $100 \mathrm{mM}$. The maximum sensitivity was obtained when the $\alpha-K G$ concentration in the working buffer was $1 \mathrm{mM}$. When the measurements were made at a concentration of $100 \mathrm{Ul}^{-1}$ ALT, where the L-glutamate/ $\alpha-K G$ ratio is changed, the optimum dose of $\alpha-K G$ and $\mathrm{L}$-alanine concentration changed to 3 and $100 \mathrm{mM}$, respectively. Considering the sensitivity of our Lglutamate biosensor for the determination of low ALT activity, dose of $1 \mathrm{mM} \alpha-\mathrm{KG}$ and $100 \mathrm{mM} \mathrm{L}$-alanine were used for the following experiments. The current increased rate of the sensor to ALT activity is linear over the range of $8-250 \mathrm{Ul}^{-1}$. Good correlation between the sensor and the Sigma ALT assay kit was achieved $\left(Y_{0}=0.5955 X_{0}-5.7318 ; R^{2}=0.9958\right)$ (Table 1$)$. The within electrode reproducibility of the sensor showed good response for $20 \mathrm{U}^{-1} \mathrm{ALT}$ on eight detections of the experiment, and yielded a relative standard deviation of $4.75 \%$.

The optimal substrate composition for measuring AST activity was also studied. A standard AST solution concentration of $30 \mathrm{U} \mathrm{I}^{-1}$ was injected into the working solution. The optimum substrate concentration for measurement of AST activity was $1 \mathrm{mM} \alpha$-ketoglutarate and $25 \mathrm{mM} \mathrm{L}$-aspartate. Fig. 2 shows amperometric current-time response curves for determining AST activity. The dynamic data are taken after the steady state of an elevated baseline has been reached. The slopes of the current-time transients were proportional to the AST activities. The responses were similar with the results of the measurement of ALT enzymatic reaction. Except under conditions of low AST activity (e.g. $50 \mathrm{U} \mathrm{l}^{-1}$ ) which shows the current decrease immediately after the serum was injected into the buffered L-aspartate and $\alpha$-ketoglutarate-containing solution. This decrease is caused by the dilution of L-aspartate when the serum sample was added, and the consequent reduction in the background current. A 2-min gate time elapsed before the current began increasing linearly 
Table 1

Sensitivity of the enzyme electrode for the measurement of MSG, AST, ALT activities

\begin{tabular}{|c|c|c|c|c|c|}
\hline Regression equation & Sensitivity $\left(\mathrm{nA} / \mathrm{min} \mathrm{U}^{-1} 1\right)$ & Range $\left(\mathrm{U}^{-1}\right)$ & Sensitivity (nA/ $\mu \mathrm{M} M S G)$ & Interference exclusion & Reference \\
\hline $\begin{array}{l}\text { AST: } Y_{1}=0.259 X_{1}-0.7178 \\
\text { ALT: } Y_{0}=0.596 X_{0}-5.7318\end{array}$ & $\begin{array}{l}0.259\left(R^{2}=0.996\right) \\
0.559\left(R^{2}=0.998\right)\end{array}$ & $\begin{array}{l}8-200 \\
8-250\end{array}$ & 12.1 & Nafion & $(\mathrm{A})^{\mathrm{a}}$ \\
\hline $\begin{array}{l}\text { AST: } Y_{3}=0.008 X_{3}-0.45 \\
\text { ALT: } Y_{4}=0.012 X_{4}+0.46\end{array}$ & $\begin{array}{l}0.008 \\
0.012\end{array}$ & $\begin{array}{l}<1700 \\
<1700\end{array}$ & Not shown & - & $(\mathrm{B})^{\mathrm{b}}$ \\
\hline $\begin{array}{l}\text { AST: } Y=0.04 X-0.2 \\
\text { ALT: } Y=0.09 X-5.2\end{array}$ & $\begin{array}{l}0.04 \\
0.09\end{array}$ & $\begin{array}{l}5-1200 \\
5-1200\end{array}$ & 0.001 & $\begin{array}{l}\text { Cellulose } \\
\text { Acetate }\end{array}$ & $(\mathrm{C})^{\mathrm{c}}$ \\
\hline ALT: $Y=0.0576 X+0.706$ & 0.058 & $<200$ & Not shown & - & $(D)^{\mathrm{d}}$ \\
\hline
\end{tabular}

${ }^{\text {a }}$ Results obtained from presented biosensor $(n=10)$.

b Measurement were carried out at a poly(vinyl chloride)/pyruvate oxidase and oxalacetate decarboxylase co-immobilizes electrode (Kihara et al., 1984a,b).

c Measurement were carried out at a cellulose acetate membrane/L-glutamate oxidase and polycarbonate membrane electrode (Compagnone et al., 1992).

d Measurement were carried out by adding lactate dehydrogenase, NADH, $\alpha-\mathrm{KG}$ and L-alanine in solution (He and Chen, 1997).

with the extension of reaction time. Accordingly, the rate of increase in the current was measured from two minutes after the sample was added to detect AST activity. The AST activity can be determined within $4 \mathrm{~min}$. The slopes ( $\mathrm{nA} / \mathrm{min}$ ) obtained from various AST standard solutions were plotted against the AST activity determined by the AST assay kits over the range of 8-200 U1 ${ }^{-1}\left(Y_{1}=0.259 X_{1}-0.7178, R^{2}=0.998, n=10\right)$ to yield a calibration graph (Table 1). The within electrode reproducibility of the sensor showed good response for $50 \mathrm{U}^{-1}$ AST on eight detections of the experiment, and yielded a relative standard deviation of $3.03 \%$.

\subsection{Sequential determination of AST and ALT activity}

This study performed sequential determination of AST and ALT activity by adding L-alanine into the reaction cell after the measurement of AST activity. A sample containing $50 \mathrm{U}^{-1}$ AST and $50 \mathrm{U}^{-1}$ ALT was injected into the buffered L-aspartate and $\alpha$-ketoglutarate containing solution. This procedure yielded a current-time curve with a current increase rate (slope) of $12.6 \mathrm{nA} / \mathrm{min}$ (Fig. 3A), which agreed with the calculation result from using the regression equation derived from the mea-

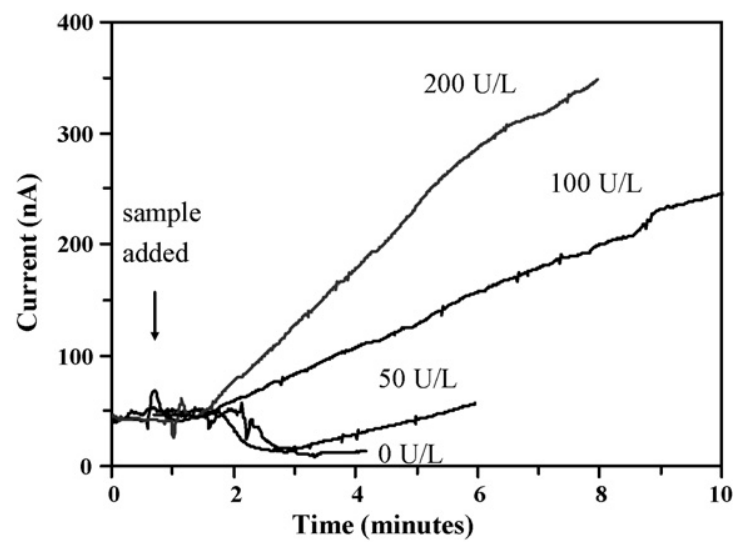

Fig. 2. Current-time curves for the L-glutamate sensor by adding 50, 100 and $200 \mathrm{U}^{-1}$ AST to the buffered L-aspartate and $\alpha$-ketoglutarate solution. The sensor was operated in $0.1 \mathrm{M} \mathrm{PBS}$ buffer ( $\mathrm{pH}$ 7.0) containing $1 \mathrm{mM} \alpha$-ketoglutarate and $25 \mathrm{mM}$ L-aspartate at $35^{\circ} \mathrm{C}$. The polarizing potential applied to the sensor was $0.4 \mathrm{~V}$ vs. $\mathrm{Ag} / \mathrm{AgCl}$. surement of AST as described above (Table 1). Five minutes following sample injection, L-alanine was added to the solution at concentrations of 100,50 and $20 \mathrm{mM}$, respectively. When 100 and $50 \mathrm{mM}$ L-alanine were tested, the slope of current-time curve did not increase, but increased $3.8 \mathrm{nA} / \mathrm{min}$ when $20 \mathrm{mM}$ L-alanine was used (Fig. 3A). Therefore, the substrate concentrations of 100 and $50 \mathrm{mM} \mathrm{L}$-alanine were unsuitable for sequential determination of AST and ALT activity. This finding did not agree with the findings of previous studies, which exhibited a significantly increased response for measurement of ALT enzymatic reactions when applied to working solutions containing
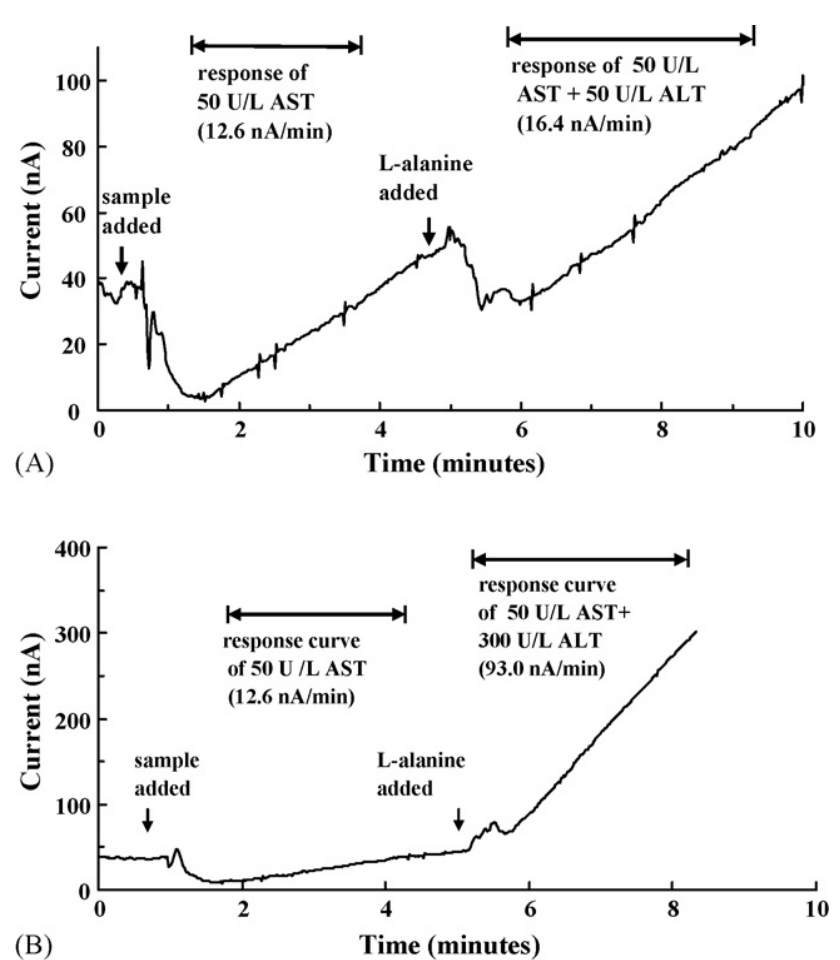

Fig. 3. Response curve of the L-glutamate sensor for sequencing detection of AST and ALT activity in serum. The activity of AST is $50 \mathrm{U} 1^{-1}$ and ALT are (A) $50 \mathrm{Ul}^{-1}$ and (B) $300 \mathrm{Ul}^{-1}$, respectively. L-Alanine was added $5 \mathrm{~min}$ after the sample added. The sensor was operated in $0.1 \mathrm{M} \mathrm{PBS}$ buffer $(\mathrm{pH} 7.0)$ containing $25 \mathrm{mM} \mathrm{L}$-aspartate and $1 \mathrm{mM} \alpha$-ketoglutarate at $35^{\circ} \mathrm{C}$. The polarizing potential applied to the sensor was $0.4 \mathrm{~V}$ vs. $\mathrm{Ag} / \mathrm{AgCl}$. 
more than $100 \mathrm{mM}$ L-alanine (Mizutani et al., 1998; Chang et al., 2003). It is postulated that L-alanine itself only slightly inhibits L-GLOx (Fig. 1), but can synergistically inhibit L-GLOx activity when combined with L-aspartate. This is only a hytpothesis raised by the authors and that further experiments are required to fully study such hypothesis. To reduce the synergistically inhibit L-GLOx by L-alanine and L-aspartate, $20 \mathrm{mM}$ L-alanine was used in the following experiment. Fig. 3B shows a sample containing $300 \mathrm{Ul}^{-1}$ ALT and $50 \mathrm{Ul}^{-1}$ AST was added and evenly distributed via the magnetic stirrer in the reaction cell. L-Alanine was added into the reaction cell when the current began to increase linearly with time $(12.6 \mathrm{nA} / \mathrm{min})$. Upon the addition of L-alanine, the current-time curve slopes increased to $93 \mathrm{nA} / \mathrm{min}$. A slope increase of $80.4 \mathrm{nA} / \mathrm{min}$ was found, and was caused by the ALT catalytic reaction upon the addition of L-alanine. It shows that the ALT activity could be determined sequentially by adding L-alanine into the solution after the measurement of AST activity. A follow up experiment for sequentially determining AST and ALT activity was presented as follows.

For sequentially determining AST and ALT activities, a sample solution containing (1) $50 \mathrm{Ul}^{-1}$ AST and $50 \mathrm{Ul}^{-1}$ ALT, (2) $50 \mathrm{Ul}^{-1} \mathrm{AST}$ and $100 \mathrm{Ul}^{-1} \mathrm{ALT}$, (3) $50 \mathrm{Ul}^{-1} \mathrm{AST}$ and $200 \mathrm{Ul}^{-1}$ ALT, (4) $50 \mathrm{Ul}^{-1}$ AST and $300 \mathrm{Ul}^{-1}$ ALT was injected into the L-aspartate and $\alpha$-ketoglutarate containing buffer. Current-time curves with slopes of 13.5, 13.4, 12.6 and $12.4 \mathrm{nA} / \mathrm{min}$, respectively, were obtained upon the addition the enzyme solution. The current increased owing to the AST catalytic reaction. The difference in response between AST/ALT containing samples and AST containing samples was negligible compared with the result calculated using the regression equation obtained from the directly AST determination (Table 1). Accordingly, the proposed sequential determination of the AST and ALT activity methods could be applied to AST activity determination. ALT activity was sequentially determined by adding L-alanine to the solution after the current began to increase linearly with time. The difference in slope following the addition of L-alanine was 3.8, 11.2, 40.1 and $80.4 \mathrm{nA} / \mathrm{min}$ for 50 , 100, 200 and $300 \mathrm{U}^{-1}$ ALT, respectively. A linear relation $\left(Y_{2}=0.3097 X_{2}-16.456, R^{2}=0.978\right)$ was identified between the difference in slope and the ALT activity determined using the ALT assay kits over the range 50-300 $\mathrm{Ul}^{-1}$. Compared with the calculation result from using the regression equation $\left(Y_{0}=0.596 X_{0}-5.7318 ; R^{2}=0.996\right)$ derived from the directly ALT measurement procedure (Table 1), the results obtained using the proposed sequentially determined procedure were lower than responses obtainer from the direct procedure for the measurement of ALT activity. It is postulated that the lower response may result from the L-alanine synergistically inhibit L-glutamate oxidase (L-GLOx) activity when combined with L-aspartate and that mass transfer may also contribute. No definitive conclusion can be taken from the results presented and further experiments are required. To achieve a sensitive response, membrane thickness, substrate concentration and signal acquisition time should be optimized since concentration gradients are generated resulting in different local concentration near the electrode surface. Although the L-glutamate sensor was inhibit by L-alanine and L-aspartate, the signal obtained using the proposed sequentially determined procedure for determination of AST and ALT activity had 30-fold greater sensitivity than the sensor based on oxalacetate decarboxylase and pyruvate oxidase described in a previous article (Kihara et al., 1984a,b) which had sensitivities of $8.34 \times 10^{-3}$ and $1.21 \times 10^{-2} \mathrm{nA} / \mathrm{min}^{-1} 1$ of AST and ALT, respectively. Whereas the proposed sequential procedure had sensitivities of 0.259 and $0.326 \mathrm{nA} / \mathrm{min}^{-1} 1$ for AST and ALT, respectively.

\subsection{The interference elimination}

Fig. 4A shows the current-time curves measured for $0.1 \mathrm{mM}$ MSG solution by the L-glutamate biosensor covered with Nafion membrane. Compared with the sensor without Nafion covered, responses decrease $95 \%$ and $40 \%$, respectively when 2.0 and $1.0 \mu \mathrm{l}$ of Nafion solution was used. Apparently, the Nafion membrane would add an additional diffusion barrier, thereby lower the flux of hydrogen peroxide to the electrode surface (Zhang et al., 1994). When the Nafion decreased to $0.5 \mu l$, the membrane does not cause any observable influence on the response of the biosensor (data not shown). Therefore, $0.5 \mu l$ Nafion solution was used for the fabrication of the L-glutamate biosensor in the following experiment.
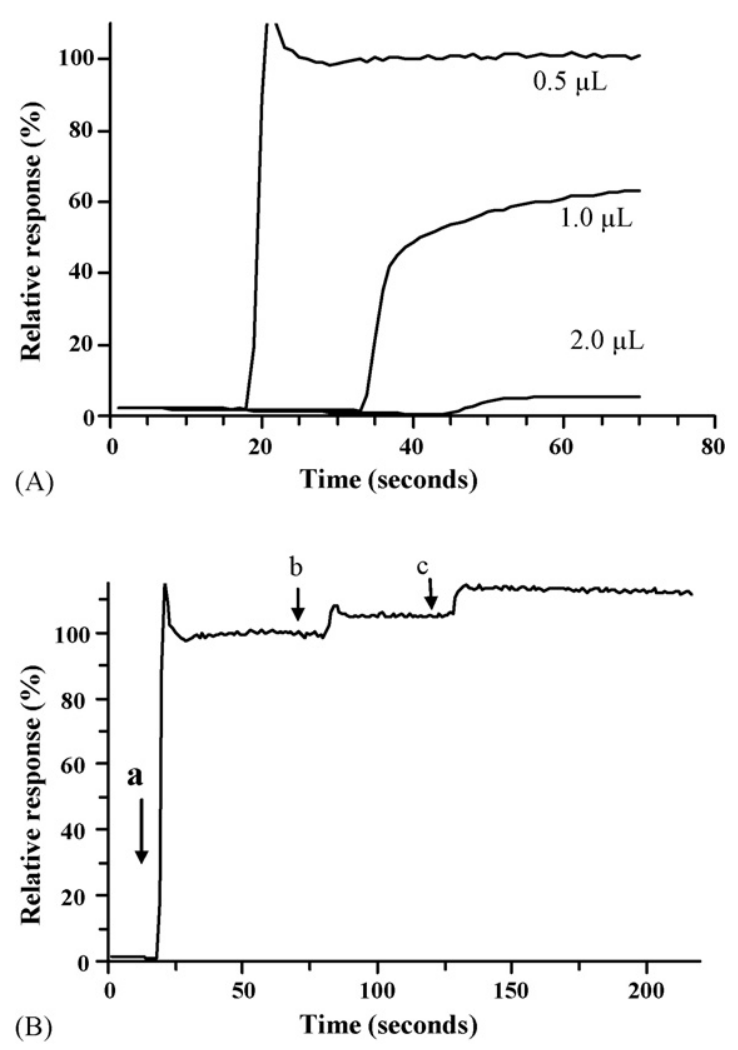

Fig. 4. (A) Response curve of the L-glutamate sensor by placing $0.5,1.0$ and $2.0 \mu \mathrm{l}$ Nafion on top of the electrode surface. Measurements were carried out with $100 \mu \mathrm{M}$ L-glutamate as substrate. (B) Response curves of the L-glutamate electrode exposed to (a) $0.1 \mathrm{mM}$ MSG, (b) $0.1 \mathrm{mM}$ ascorbic acid and (c) $0.1 \mathrm{mM}$ uric acid to the reaction cell. The Pd was modified with $0.5 \mu l$ Nafion. The sensor was operated in $0.1 \mathrm{M}$ PBS buffer $(\mathrm{pH} 7.0)$ at $35^{\circ} \mathrm{C}$. The polarizing potential applied to the sensor was $0.4 \mathrm{~V}$ vs. $\mathrm{Ag} / \mathrm{AgCl}$. 
The interference eliminating effect of a Nafion membrane to $0.1 \mathrm{mM}$ ascorbic acid and uric acid is shown in Fig. 4B. The percent of response for $0.1 \mathrm{mM}$ ascorbic acid and uric acid to that for $0.1 \mathrm{mM}$ MSG (interference level) is $5 \%$ and $8 \%$, respectively. However, with conventional electrode, the interference levels (the ration of electrochemical response to interferent to the electrochemical response of glutamate for AA and UA were more than $100 \%$ (data not shown). It is postulated that Nafion, an anionic polymer, shows significant effect to eliminate the interference of AA and UA. This interference level is far from sufficient to detection glutamate concentration in neurochemical solution where ascorbic acid levels are two orders of magnitude greater than glutamate (Pan and Arnold, 1996). However, this is not necessarily the case with the measurement of ALT and/or AST activity in serum, since the determination of AST and ALT activities were based on kineticbased electrochemical method, the concentration of L-glutamate increases with the extension of reaction time. Basically, the interference of electrochemically active species was negligible on a dynamical aminotransferase determination when the dynamic data are taken after the steady state of an elevated baseline has been reached (Chang et al., 2003; Upadhyaya et al., 2006).

It is difficult to make another membrane adhere on the Nafion membrane, a fluorine-containing material (Gogol et al., 2000). The high viscosity of PVA-SbQ makes it possible to encapsulate the Nafion-covered electrode strip with an immobilized enzyme (Chang et al., 2003). The PVA-SbQ membrane has been reported to show as a protected membrane with cutoff of ca. 1000-Da (Mizutani et al., 1995). Protein and other substrate with large molecular weight can be excluded by this membrane. Therefore, the PVA-SbQ was used to immobilize the L-glutamate oxidase on the surface of Nafion covered Pd electrode. In a preliminary experiment, the PVA-SbQ membrane could swell after it was immersed in the buffer, and showed a rapid response to MSG $(11.65 \mathrm{nA} / \mathrm{min} \mu \mathrm{M})$ with six-fold faster than that of the freshly fabricated electrode $(1.99 \mathrm{nA} / \mathrm{min} \mu \mathrm{M})$. Therefore, the electrode had to be immersed in phosphate buffer to achieve a rapid and stable response.

Fig. 5 shows the response curves of the proposed Nafion modified Pd L-glutamate sensor to ALT. The current increased with extension of reaction time upon the adding of the $50 \mathrm{U}^{-1}$ standard ALT solution (Fig. 5, line a). Current-time curve with a slope of $21.992 \mathrm{nA} / \mathrm{min}$ was obtained upon the addition the enzyme solution. While for the sample containing ascorbic acid, an elevation of the baseline (ca. $80 \mathrm{nA}$ ) was found (Fig. 5, line b). Despite the electrode was coated with Nafion membrane, this membrane was not sufficient to prevent the ascorbic acid to reach to the electrode, subsequently causing the increasing of current. In order to prevent the interference, data must be taken after the interference response reaches an elevated baseline response. In this experiment, a 1-min gate time elapsed before the current began increasing linearly was required. As shown in Fig. 5, line b, a slope of $21.099 \mathrm{nA} / \mathrm{min}$ was obtained, the result revealed that the interference of $1 \mathrm{mM}$ ascorbic acid was negligible on a dynamical ALT determination.

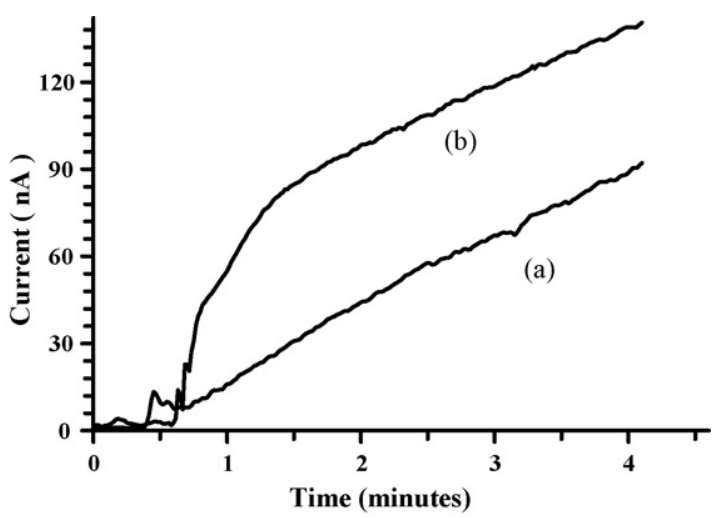

Fig. 5. Response of the Nafion modified Pd L-glutamate sensor to (a) $50 \mathrm{U} 1^{-1}$ ALT and (b) $50 \mathrm{U}^{-1}$ ALT mixed with $1 \mathrm{mM}$ ascorbic acid. The sensor was operated in $0.1 \mathrm{M}$ PBS buffer ( $\mathrm{pH} 7.0$ ) containing $1 \mathrm{mM} \alpha$-ketoglutarate and $100 \mathrm{mM} \mathrm{L}$-alanine at $35^{\circ} \mathrm{C}$. The polarizing potential applied to the sensor was $0.4 \mathrm{~V}$ vs. $\mathrm{Ag} / \mathrm{AgCl}$.

\subsection{Comparison of proposed $\mathrm{L}$-glutamate biosensor with other $\mathrm{L}$-glutamate biosensor for the measurement of L-glutamate, AST and ALT activity}

Interestingly, comparison of the response and sensitivity obtained from proposed L-glutamate biosensor (ca. $12 \mathrm{nA} / \mu \mathrm{M}$; detection limit $0.05 \mu \mathrm{M}$ ) with that of previous article described by Compagnone et al. ( $1 \mathrm{nA} / \mathrm{mM}$; detection limit $0.5 \mu \mathrm{M}, 1992)$ for the measurement of L-glutamate revealed that the former biosensor obtained sensitivity by 12,000 -fold. However, for the measurement of ALT activity, the proposed biosensor $\left(0.559 \mathrm{nA} / \mathrm{min}^{-1} 1\right)$ only achieve a six-fold response than previous result $\left(0.09 \mathrm{nA} / \mathrm{min}^{-1} 1\right)$ (Table 1). It depicts that, for the mesurement of L-glutamate, the proposed L-glutamate biosensor is far more sensitive than that of Compagnone's. Unfortunately, for the measurement of aminotransferase activity, the proposed L-glutamate biosensor was restrained because the L-GLOx was inhibited by $\alpha$-ketoglutarate, thereby decreasing the sensitivity. The sensitivity of the proposed sensor can be improved by using substrate initiation procedure instead of enzyme initiation procedure to prevent the inhibition of substrate. On the other hand, for obtaining a precise result, the proposed biosensor had to take data after the interference response reached an elevated baseline response because the Nafion film was not sufficient to prevent the ascorbic acid to reach to the electrode. This finding conflicts with previous article, which obtained data as soon as the adding of sample (Compagnone et al., 1992; Mizutani et al., 1998). It is probable those size exclusion film described by previous article are more efficient than Nafion membrane for the elimination of electrochemical active species, most of the ascorbic acid and uric acid was trapped by the cellulose acetate (Compagnone et al., 1992) and/or polyion (Mizutani et al., 1998). Nevertheless, the pore of those size exclusion membrane would block by ascorbic acid and uric acid and poisoned the electrode. The reliability and the response of such electrodes decrease with repeated use due to the electrode fouling by oxidized ascorbic acid.

Although the proposed sensor was inhibited by $\alpha$ ketoglutarate and Nafion film was not sufficient to prevent the 
ascorbic acid to reach to the electrode, the proposed sensor possessed several advantages over other sensor reported in literature: (1) Nafion is a perfluorinated cation exchange polymer with a hydrophobic $\left(-\mathrm{CF}_{2}-\mathrm{CF}_{2}-\right)$ backbone and hydrophilic sulfonic acid groups $\left(-\mathrm{SO}_{3} \mathrm{H}\right)$ which contributes its electronwithdrawing effect (Anh et al., 2003). Therefore, Nafion membrane can prevent the blocking of ascorbic acid and uric acid. (2) Palladium electrode could effectively restrict the oxidized anionic interferent to adhere on its surface, thereby the fouling of the electrode was avoided. (3) The fabricated Lglutamate biosensor exhibited remarkable long-term stability. Most of the functional characteristics could be restored within five minutes (wet-up times) of repeated wetting and drying. (4) The proposed procedure provides adequate sensitivity and reproducibility to the measurement of AST and ALT. (5) The proposed sensor enables users to measure both AST and ALT activities sequentially.

\section{Conclusions}

Previous studies focused on exclusion of the electroactive species from the sized exclusion membrane during the amperometric measurement of AST and ALT activities. However, the problem of electrode fouling is a critical issue which would cause a serious decrease of the current, thereby interfering of the response. Our preliminary results show that the described Nafion modified palladium can efficiently prevent the surface fouling problem of the electrode. Despite the cation exchange membrane was not sufficient to prevent the ascorbic acid to reach to the electrode, we can take data after the interference response reached an elevated baseline response. By using the proposed biosensor, the interference of $1 \mathrm{mM}$ ascorbic acid was negligible on a dynamical aminotransferase determination when the dynamic data are taken after the steady state of an elevated baseline has been reached. The rate of signal increase obtained by our sensor for the measurement AST and ALT activity was 0.259 and $0.559 \mathrm{nA} / \mathrm{min}^{-1} 1$. Signals obtained by our sensor were more than six-fold sensitive than the biosensor for the measurement of aminotransferase described in previous paper. For the sequentially measurement of AST and ALT activity, the proposed method had 30 -fold greater sensitivity than the sensor based on oxalacetate decarboxylase and pyruvate oxidase described in a previous article (Kihara et al., 1984a,b) which had sensitivities of $8.34 \times 10^{-3}$ and $1.21 \times 10^{-2} \mathrm{nA} / \mathrm{min} \mathrm{U}^{-1} 1$ of AST and ALT, respectively. Whereas the proposed sequential procedure had sensitivities of 0.259 and $0.326 \mathrm{nA} / \mathrm{min}^{-1} 1$ for AST and ALT, respectively.

The combination of the nafion membrane and palladium electrode allows achievement of high sensitivity with high relia- bility upon repeating measurements. It can be expected that, by optimizing the procedures and reagent compositions e.g. using substrate initiation procedure instead of enzyme initiation procedure to prevent the inhibition of substrate, combination of a portable measuring device with the sensor strip developed in this study. Useful and cost-efficient operation biosensor can be developed for the rapid screening of aminotransferase is possible.

\section{References}

Anh, D.T.V., Olthuis, W., Bergveld, P., 2003. Sensor Actuat. B 91, 1-4. Arya, S.P., Mahajan, M., Jain, P., 2000. Anal. Chim. Acta 417, 1-14.

Chang, K.S., Hsu, W.L., Chen, H.Y., Chang, C.K., Chen, C.Y., 2003. Anal. Chim. Acta 481, 199-208.

Clark, L.C., 1987. In: Turner, A.P.F., Karube, I., Wilson, G.S. (Eds.), Biosensors, Fundamentals and Applications. Oxford Science Publications, New York, p. 11.

Compagnone, D., Federici, G., Massouud, R., Santoro, L., Anichini, M., Palleschi, G., 1992. Clin. Chem. 38, 2306-2310.

Cooper, J.M., McNeil, C.J., Spoors, J.A., 1991. Anal. Chim. Acta 245, 57-62.

Geise, R.J., Adams, J.A., Barone, N.J., Yacynych, A.M., 1991. Biosen. Bioelectron. 6, 151-161.

Gogol, E.V., Evtugyn, G.A., Marty, J.L., Budnikov, H.C., Winter, V.G., 2000. Talanta 53, 379-389.

He, Y.N., Chen, H.Y., 1997. Anal. Chim. Acta 353, 319-323.

Issberner, J.P., Schauer, C.L., Trimmer, B.A., Walt, D.R., 2002. J. Neurosci. Meth. 120, 1-10.

Johnston, D.A., Cardosi, M.F., Vaughan, D.H., 1995. Electroanalysis 7, 520-526.

Karmen, A., 1955. J. Clin. Invest. 34, 131-133.

Kihara, K., Yasukawa, E., Hirose, S., 1984a. Anal. Chem. 56, 1876-1880.

Kihara, K., Yasukawa, E., Hirose, M., 1984b. Anal. Chim. Acta 159, 81-86.

Kusakabe, H., Midorikawa, Y., Fujishima, T., Kuninaka, A., Yoshino, H., 1983. Agric. Biol. Chem. 47, 1323-1328.

Lim, S.H., Wei, J., Lin, J., Li, Q., You, J.K., 2005. Biosens. Bioelectron. 20, 2341-2346.

Magner, E., 1998. Analyst 123, 1967-1970.

Mizutani, F., Sato, Y., Sawaguchi, T., Yabuki, S., Iijima, S., 1998. Sensor Actuat. B 52, 23-29.

Mizutani, F., Yabuki, S., Hirata, Y., 1995. Anal. Chim. Acta 314, 233-239.

Matos, R.C., Augelli, M.A., Lago, C.L., Angnes, L.L., 2000. Anal. Chim. Acta 404, 151-157.

Moussyd, F., Harrison, D.J., O’Brien, D.W., Rajotte, R.V., 1993. Anal. Chem. 65, 2072-2077.

Nagy, G., Xu, C.X., Buck, R.P., 1998. Anal. Chem. 70, 2156-2161.

Pan, S., Arnold, M.A., 1996. Talanta 44, 1157-1162.

Pournaghi-Azar, M.H., Ojani, R., 1997. Talanta 44, 297-303.

Reitman, S., Frankel, S., 1957. Am. J. Clin. Pathol. 28, 56-63.

Rietz, B., Guilbault, G.G., 1975. Anal. Chim. Acta 77, 191-198.

Shi, M.D., Master Thesis of Graduate Institute of Medicine. Kaohsiung Medical University, Kaohsiung, Taiwan. 1997, p. 1.

Uollenberger, W., Scheller, F.W., Boehmer, A., Passarge, M., Mueller, H.-G., 1989. Biosensors 4, 381-391.

Upadhyaya, S., Ohgamia, N., Kusakabe, H., Suzuki, H., 2006. Biosens. Bioelectron. 21, 1230-1236.

Zhang, Y., Hu, Y., Wilson, G.S., Moatti-Sirat, D., Poitout, V., Reach, G., 1994. Anal. Chem. 66, 1183-1188. 